stronger protections for human research subjects in 2000. "There's more recognition that research participants aren't just individuals, they are part of families and communities. What's interesting is to see the evolution of thinking around these things."

University of Toronto Professor of Public Health Lorraine Ferris says the guidelines provide much-needed clarification, while being responsive to community concerns.

But Ferris and McDonald raise concerns that the document does not fully address institutional potential conflicts of interest. In the past, clinical trials involving drugs and medical devices usually took place in academic settings, even if a pharmaceutical company was the external sponsor of the trial. The research was then governed by the institution's Research Ethics Board.

Today, the institutions themselves sponsor clinical trials, and that could put them in a potential conflict, say Ferris and McDonald. "There needs to be more clarity around how the institution applies the rules," Ferris says.

In addition, McDonald believes Research Ethics Boards at institutions should not report to the vice-president of research, because that job involves promoting and attracting research and research dollars - to the institution. If a board discovers an ethical problem with research, that finding puts the vice-president into the tense situation of wondering how action regarding the problem will affect his or her ability to attract dollars.

Boards should report to another administrator, McDonald says. "There is a real conflict of roles here."

Susan Zimmerman, executive director of the Secretariat on Research Ethics, which provides administrative support to the advisory panel, says feedback on the proposed changes has thus far been positive. "Obviously whatever the policy statement says, it is just about the conduct of research itself. How we in this country govern research is a separate issue. We have been involved in that dialogue but that is separate from the policy statement itself." — Laura Eggertson, CMAJ

DOI:10.1503/cmaj.090093

\title{
Failing grade for public-private partnership hospitals
}

$\mathrm{O}$

ntario could have saved hundreds of millions of dollars if the Brampton Civic Hospital had been built and operated publicly rather than under a public-private partnership (P3), Ontario Auditor General Jim McCarter says.

The government could have saved almost $\$ 100$ million on the cost of design, construction and provision of nonclinical services if it had followed traditional procurement methods. Because the government can obtain lower interest rates, another $\$ 200$ million in savings could have accrued had the government, rather than industry, borrowed money for the project, McCarter wrote in his 2008 annual report (www.auditor.on.ca/en/reports_en/en08 1303en08.pdf).

The Brampton Civic Hospital was the first built in Ontario using the P3 funding model, under which the government pays a private consortium to design, build and finance a hospital, and in some cases to provide nonclinical services such as laundry, food and security (CMAJ 2008;179[9]:883-5). Ontario has planned or started construction on more than 30 such healthrelated P3 projects, which have drawn considerable criticism (CMAJ 2008; 179[10]:991-4).

McCarter's report, the most thorough review to date of a P3 hospital done by an auditor general, supports some of the criticism, saying that costs and benefits weren't adequately assessed.

The "value for money" assessment was overestimated by $\$ 634$ million, while the cost of construction using the P3 model nearly doubled. The value of "risk transfer," the estimate of what it will cost the consortium to deliver the project on time, was also overestimated by a wide margin, according to $\mathrm{Mc}$ Carter. Proponents of P3s say risk transfer is one of the major benefits of this funding model.

P3 opponents, such as Natalie Mehra, director of the Ontario Health Coalition, say they've been vindicated by the findings. Paul Moist, Canadian Union of Public Employees national

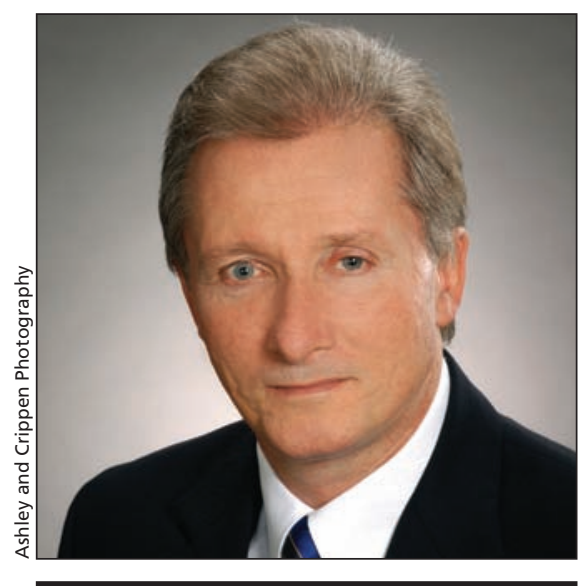

Ontario Auditor General Jim McCarter

president, adds that the report "confirms our worst expectations that this was a boondoggle."

The government agency responsible for overseeing P3 projects says all problems have since been solved, while recommendations for improving transparency, accountability and value-formoney assessments have been adopted.

Infrastructure Ontario Manager of Corporate Relations Doug DeRabbie also says summaries of value-for-money assessments are available on the crown corporation's website, although full reports aren't posted because they contain sensitive material (www.infrastructureontario.ca/en/projects/index.asp).

But these summaries, which are short and have some information blacked out, indicate only a lack of openness and transparency, says Mehra, who says its disingenuous to claim that value-for-money assessments are publicly available. "All they do is compare the bottom lines. That is not a value-for-money audit."

The Ontario Health Coalition is calling for a moratorium on $\mathrm{P} 3 \mathrm{~s}$, pending a public review. The British Columbia chapter of the Canadian Union of Public Employees has renewed calls for the province's auditor general to closer scrutinize P3 projects. "We think it's an equally bad story," Moist says. Erika Gilbert, Ottawa, Ont.

DOI: $10.1503 / \mathrm{cmaj} .090065$ 